\title{
Adrenoleukodystrophy in a mother and son
}

\author{
RODERICK H W SIMPSON,* JOHN RODDA, $\dagger$ CAROLUS J REINECKE $\ddagger$ \\ From the Postgraduate Medical School,* University of Exeter, UK, Department of Neurology, $\dagger$ Baragwanath \\ Hospital, Johannesburg, and Department of Biochemistry, $\ddagger$ Potchesfstroom University for CHO, \\ Potchesfstroom, Transvaal, South Africa
}

SUMMARY A 6 year old boy died from a degenerative brain disease which was clinically and pathologically typical of adrenoleukodystrophy. Shortly before his disease became manifest his 28 year old mother had presented with similar symptoms, and subsequently died. Her brain showed almost identical features including the presence of pathognomonic ultrastructural inclusions. The accumulation of very long chain fatty acids in cerebral white matter as well as high hexacosanoic to docosanoic acid (C26:22) ratios, substantiated the diagnosis in both cases. This is one of the few documented cases of adrenoleukodystrophy in an adult female, and is almost certainly an example of clinical manifestation of this X-linked inherited disease in a carrier.

Adrenoleukodystrophy (ALD) is characterised clinically by progressive neurological deterioration involving mainly the pyramidal tracts together with cortical blindness. This is associated with adrenocortical insufficiency which may be silent clinically, only appearing on adrenocorticotrophic hormone (ACTH) stimulation. ${ }^{1}$ Post mortem examination reveals a sudanophil leukodystrophy involving the cerebral hemispheric white matter of mainly the occipital, parietal and posterior temporal lobes, but sub-cortical arcuate fibres are generally spared. The cerebellar white matter is affected in some cases, but the brain stem and spinal cord show degeneration of only the descending fibre tracts. In the adrenal glands ballooned cortical cells are seen in the zonae fasciculata and reticularis. ${ }^{2}$ By electron microscopy, pathognomonic cytoplasmic inclusions are found in the brain, adrenal cortex ${ }^{3}$ and some other organs. ${ }^{4}$ Biochemical studies have shown an abnormal accumulation of long chain fatty acids in the brain ${ }^{5}$ and cultured skin fibroblasts, ${ }^{6}$ and it has been suggested that ALD is a lipid storage disease, and that the basic defect may be a deficiency of one of the enzymes involved in peroxisomal oxidation of very long chain fatty acids. ${ }^{7}$

Address for reprint requests: Dr R H W Simpson, Postgraduate Medical School, University of Exeter, Barrack Road, Exeter EX2 5DW, UK.

Received 1 July 1986 and in revised form 4 February 1987. Accepted 11 February 1987
Although most cases have been described in boys of 5 to 15 years of age, older and younger individuals may also be affected. In the older group, many fall into the category of adrenomyeloneuropathy (AMN), which is clinically ${ }^{8}$ and pathologically ${ }^{9}$ different in that the spinal cord is involved much more than the brain. However, there is adrenal insufficiency, and the ultrastructural and biochemical findings are identical to those in ALD. In addition, cases of ALD and AMN have occurred in the same families, ${ }^{810}$ leading to the suggestion that both are different varieties of the same disease. ${ }^{11}$ A neonatal form of ALD has also been recognised, ${ }^{12}$ but although it shares some similarities with the other types, it is now considered to be a separate entity more closely related (but not identical) to Zellweger's syndrome and infantile Refsum's disease. ${ }^{13-15}$

With the exception of the neonatal form, which is autosomal recessive, ALD is inherited in a sex-linked recessive manner, and the gene locus itself has been accurately mapped on the $\mathrm{X}$ chromosome. ${ }^{16}$ However, a few cases of affected females other than neonates have been described ${ }^{6111^{1-21}}$ and we here report another individual studied clinically, neuropathologically and biochemically.

\section{Clinical findings}

Case 1

A previously well 28 year old black African woman presented to Baragwanath Hospital with a 4 month history of mental confusion. She had become socially withdrawn and was unable to care for herself or her family. She could 
not provide a full or accurate history, including that of her family, but she did not know of any other relations with comparable symptoms. There was an apparently normal sister, who had no issue, and the patient herself had three children: an 11 year old girl with well controlled epilepsy of long standing, a 6 year old boy (Case 2) soon to present with the same disease, and a 4 year old son who was clinically normal. Her husband had recently abandoned the family and was not traceable, but he was apparently healthy.

Upon questioning, the patient knew her name, but was disorientated for time and place, and had difficulty naming objects. She exhibited concentration fatigue, as well as easily becoming lost, but at this stage, her gait was normal. Examination revealed mild generalised weakness, and increased limb tone with brisk reflexes, but flexor plantar responses. She had a left hemianopia with normal fundi and pupillary reaction. Cranial nerves were otherwise intact. Coordination was poor, but there was no obvious loss of sensation or proprioception. Outwith the nervous system she was noted to be 30 weeks pregnant. She was normotensive (115/75), and there was no excess pigmentation.

Among investigations CT scans, including one performed shortly before death (fig 1), showed reduced density throughout the white matter with focal uptake of contrast. Lumbar puncture revealed a pressure of $3 \mathrm{~cm}$ of water, normal chemistry and no cells. Peripheral blood haematological and biochemical investigations (including urea and electrolytes) were within normal limits, and a large number of serological studies were negative. At this stage a diagnosis of

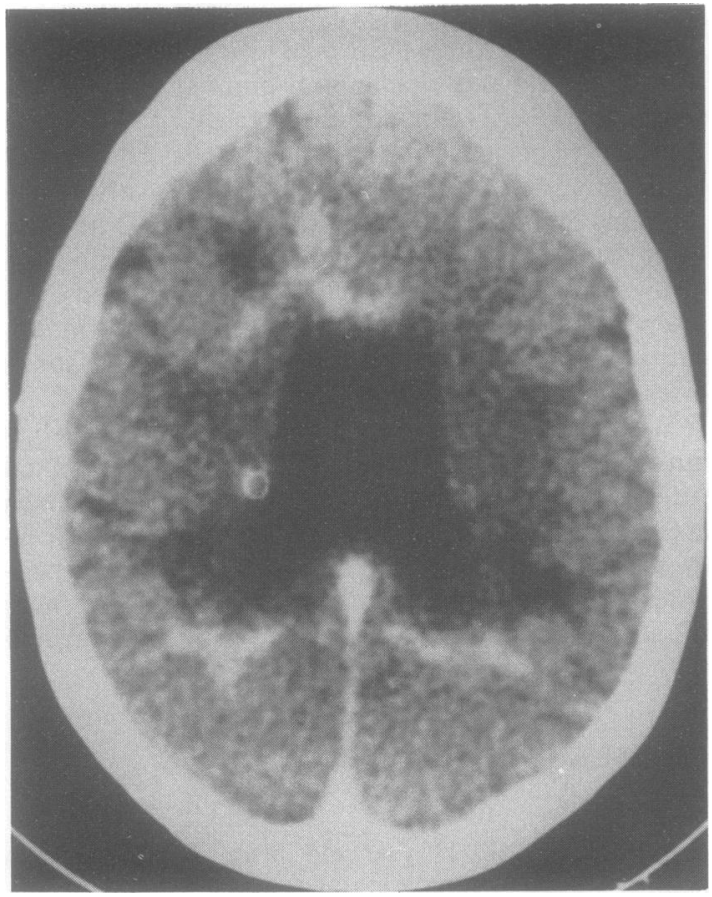

Fig 1 Case 1: CT scan showing diffuse low density of the white matter with focal uptake of contrast.
ALD was not entertained and adrenal function tests were not performed.

The patient's clinical condition deteriorated rapidly. She became more confused and was unable to feed herself, and eventually she could not even get out of bed. She was delivered of a macerated foetus, on whom no necropsy was performed. Shortly thereafter, she developed bronchopneumonia and died 5 weeks after admission.

\section{Case 2}

During the final stages of the illness of Case 1, her 6 year old son was admitted to an outlying mission hospital whence he was transferred to Baragwanath Hospital. Over a few months he had begun to exhibit strange behaviour including inappropriate outbursts of laughter, and he had also become blind. He was disorientated for time and place, but at this stage still knew his name. He had a shuffling gait and often collided with furniture. All four limbs showed some increase in tone and briskness of reflexes, but Babinsky and Hoffman reflexes were negative and sensation was normal. The blindness was cortical with normally reacting pupils and normal fundi. Other cranial nerves were intact. His growth parameters were also normal, and no obvious abnormality was found outwith the nervous system; blood pressure was $100 / 60 \mathrm{~mm} \mathrm{Hg}$ and there were no features of adrenal insufficiency.

The CT scan revealed low density throughout the white matter with uptake of contrast especially in the occipital lobes (fig 2). The EEG showed diffuse slowing in the poste-

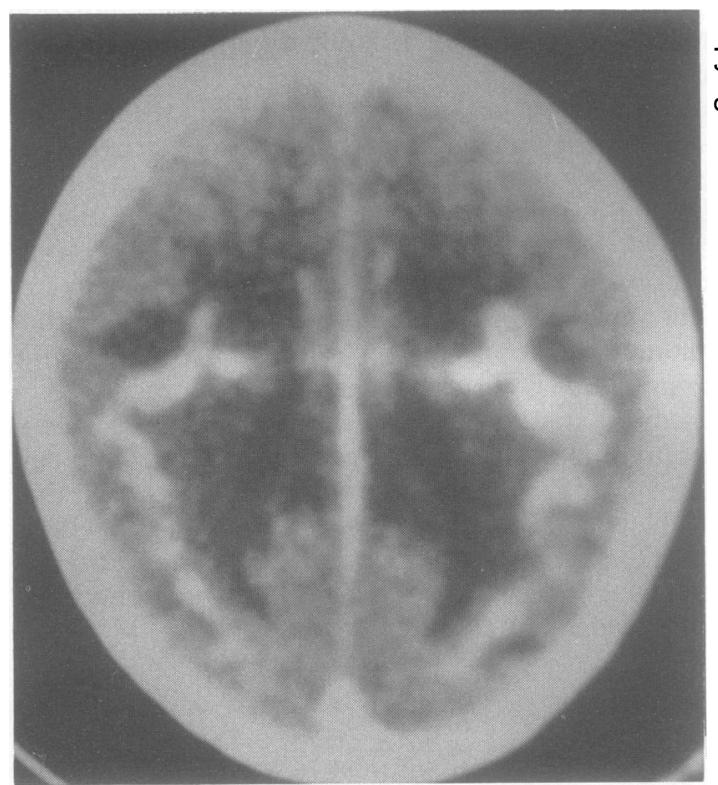

Fig 2 Case 2: enhanced CT scan also showing decreased density of the white matter with serpiginous uptake of contrast, especially in the occipital lobes corresponding to the grey matter-white matter interface. 
rior occipital areas, and visual evoked potentials confirmed the presence of cortical blindness. On lumbar puncture, the CSF pressure was $5 \mathrm{~cm}$ water; no cells were found and protein was $0.39 \mathrm{~g} / \mathrm{l}$. Routine radiological and blood investigations were non-contributory-plasma electrolytes were within the normal range. However, an ACTH stimulation test using 25 units of intramuscular ACTH showed a sub-normal response with plasma cortisol levels of $411 \mathrm{nmol} / \mathrm{l}$ at the start, 483 after 30 minutes and 538 after 60 minutes.

The diagnosis of ALD was confirmed on brain biopsy, and the patient's clinical condition progressively deteriorated over the next 9 months. He became more confused and withdrawn, developing focal seizures and generalised spasticity. He lapsed into a stuporose state, and died one year after his initial presentation.

\section{Pathological findings}

\section{Case 1}

A limited necropsy was performed 3 days after death, and only the brain was available for study. After fixation in formol saline it weighed $1175 \mathrm{~g}$. The cerebral white matter showed extensive areas of discolouration with a somewhat granular appearance. This change involved the centrum semiovale of the parietal and occipital lobes and the posterior part of the temporal lobes. It was generalised rather than patchy, although the subcortical arcuate fibres were largely spared. The white matter of the frontal and anterior temporal lobes was macroscopically unaffected. Similar changes were evident in the posterior parts of the corpus callosum and internal capsules. There was also involvement of the cerebellar white matter, as well as the cerebral pedun-

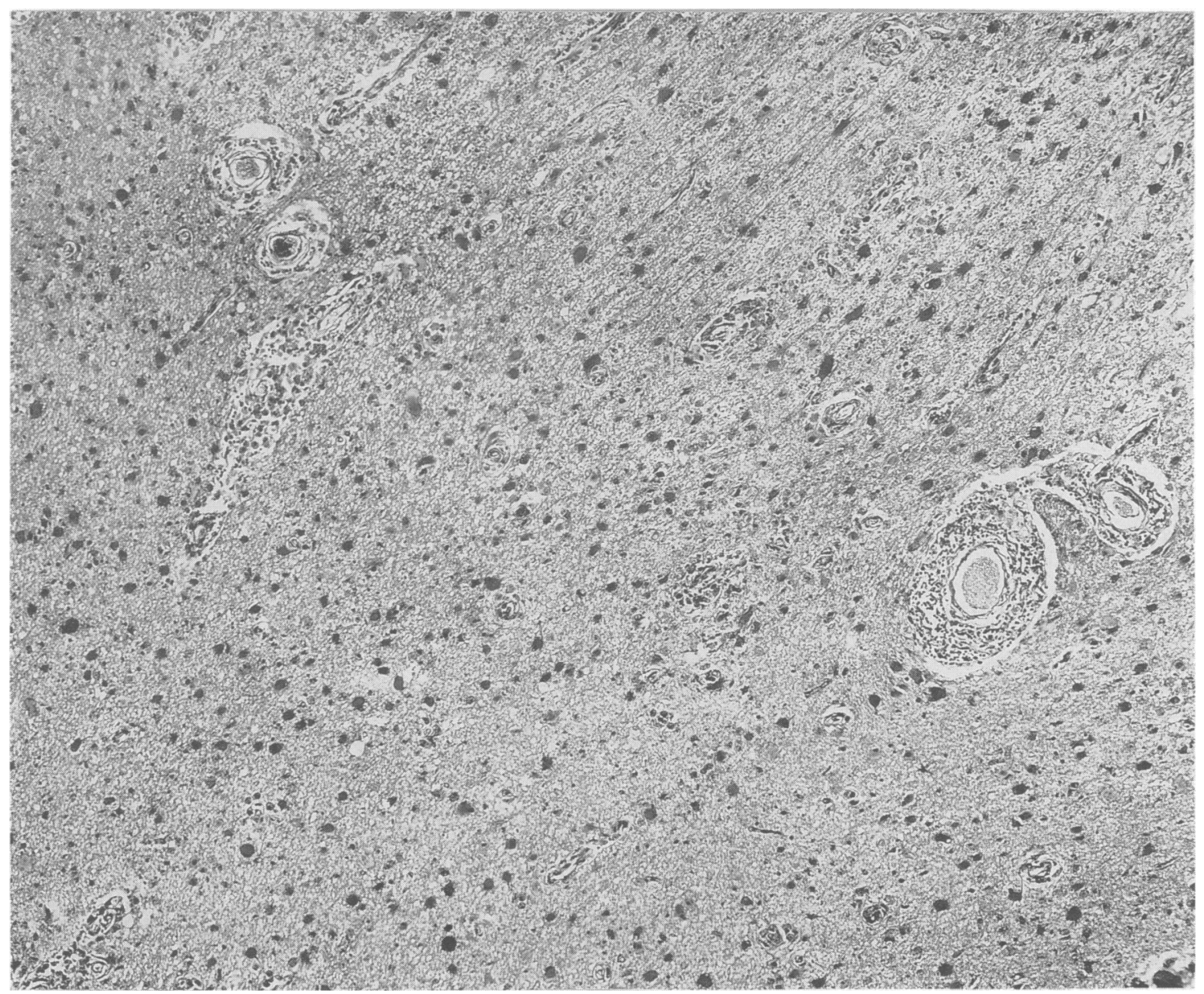

Fig 3 Case 1: micrograph of the affected brain showing perivascular accumulation of inflammatory cells, as well as astrocytic gliosis in the surrounding demyelinated white matter. (Haematoxylin and eosin, $\times 50$ ). 


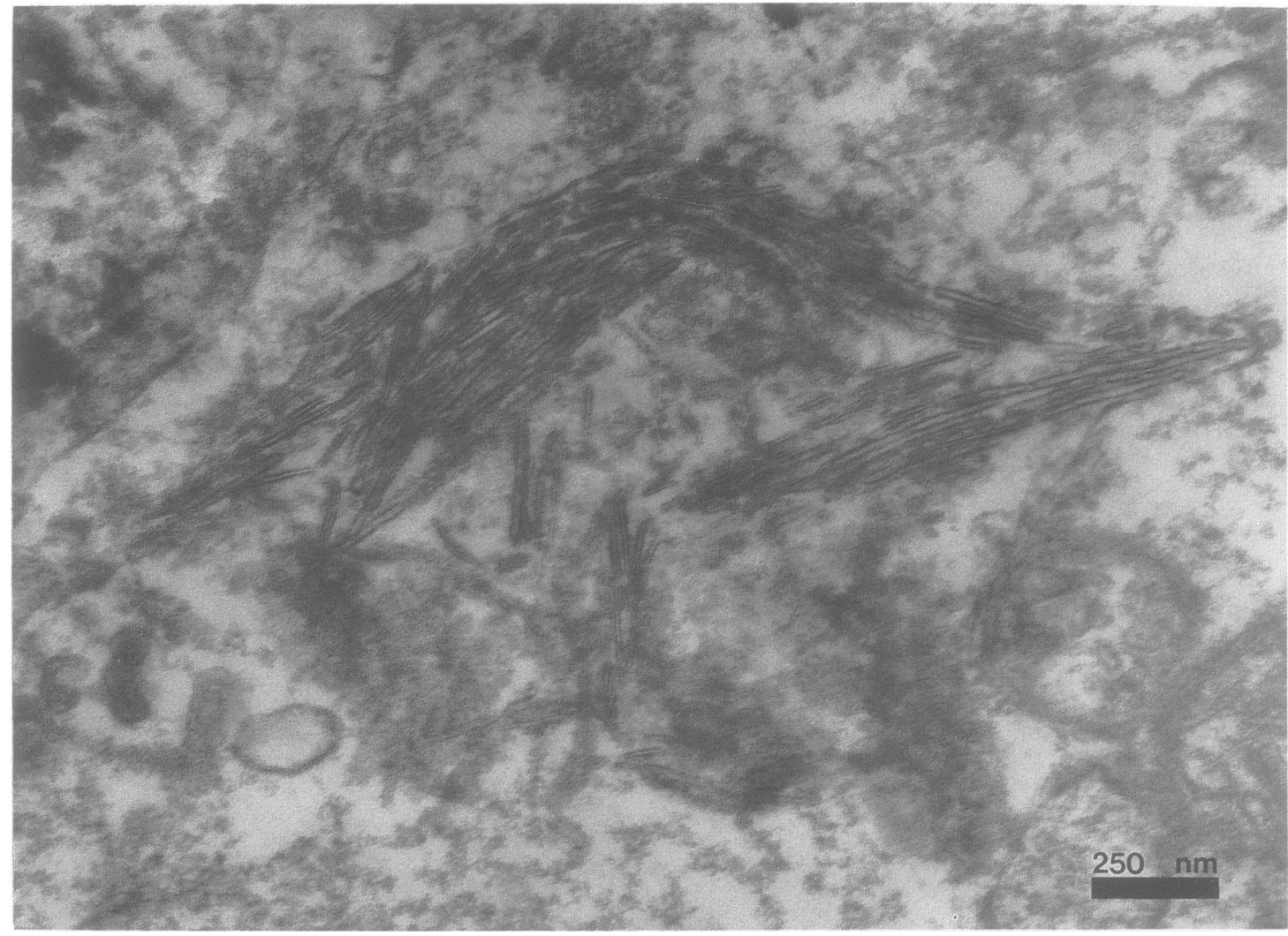

Fig 4 Case 1: electron micrograph of the affected white matter showing characteristic trilaminar inclusion bodies of ALD.

cles, medullary pyramids and long tracts of the pons. Histological examination of the abnormal areas revealed almost total loss of myelin together with astrocytic proliferation and accumulation of sudanophil material both within and without phagocytic cells. There was also a perivascular inflammatory cell infiltrate which was heavier in the parietal than in the occipital lobes (fig 3 ). Neurons were generally preserved, but any loss was considered slight in comparison to the devastation of the white matter. Electron microscopic examination of gluteraldehyde fixed white matter confirmed the loss of myelin and revealed numerous intracytoplasmic trilaminar bodies (fig 4).

\section{Case 2}

Biopsy A wedge of brain tissue was received in which the main changes were in the white matter. These comprised loss of myelin, astrocytic proliferation and perivascular aggregation of macrophages, some of which had vacuolated cytoplasm. Ultrastructural examination showed trilaminar inclusions characteristic of ALD.

Necropsy The post mortem interval was 2 days. The brain weighed $820 \mathrm{~g}$, and after representative areas had been taken for biochemical study it was fixed in formol saline for 2 months. The cerebral white matter showed generalised discolouration (fig 5) with apparent sparing of the frontal and anterior temporal lobes. The overall distribution was similar to that in Case 1 except that the cerebellum was uninvolved. In the spinal cord, only the corticospinal and pyramidal tracts were affected. The histological picture was also the same as in Case 1 with demyelination, astrocytic proliferation, accumulation of sudanophil material and a perivascular inflammatory cell infiltrate most marked in the parietal lobes. Trilaminar inclusions were identified on ultrastructural examination.

Both adrenal glands were atrophic. In the zonae fasciculata and reticularis of the cortex swollen cells were seen, the cytoplasm of which was either vacuolated or granular (fig 6). Plentiful trilaminar bodies were present by electron microscopy. In the rest of the body the only abnormality was a fibrinous pleurisy. An extensive histological and ultrastructural examination was conducted, including the testes and skin, but no other abnormality or further trilaminar bodies were found.

Biochemistry Lipids were extracted from the formalin fixed brain tissue and fractionated as previously described. ${ }^{22}$ Methylesters of the fatty acids, esterified to cholesterol, were 
analysed by capillary gas-liquid chromatography with a Hewlett Packard Model 5880 gas-chromatograph using a fused silica SP 12100 column $(10 \mathrm{M} \times 0.2 \mathrm{~mm})$.

The fatty acid content of the white matter from demyelinated areas of the brains of both cases is shown in fig 7 . We have repeatedly found ${ }^{22}$ that the very long chain fatty acids in normal brain tissue seldom exceeded the C26-type. However fatty acids of up to C30:0 were clearly detectable (fig 7A) in the brain from the boy (Case 2), whereas the pattern of distribution of the very long chain fatty acids showed the characteristic bell-shaped profile (fig 7A and B) for both the boy (Case 2) and the mother (Case 1). Moreover, the

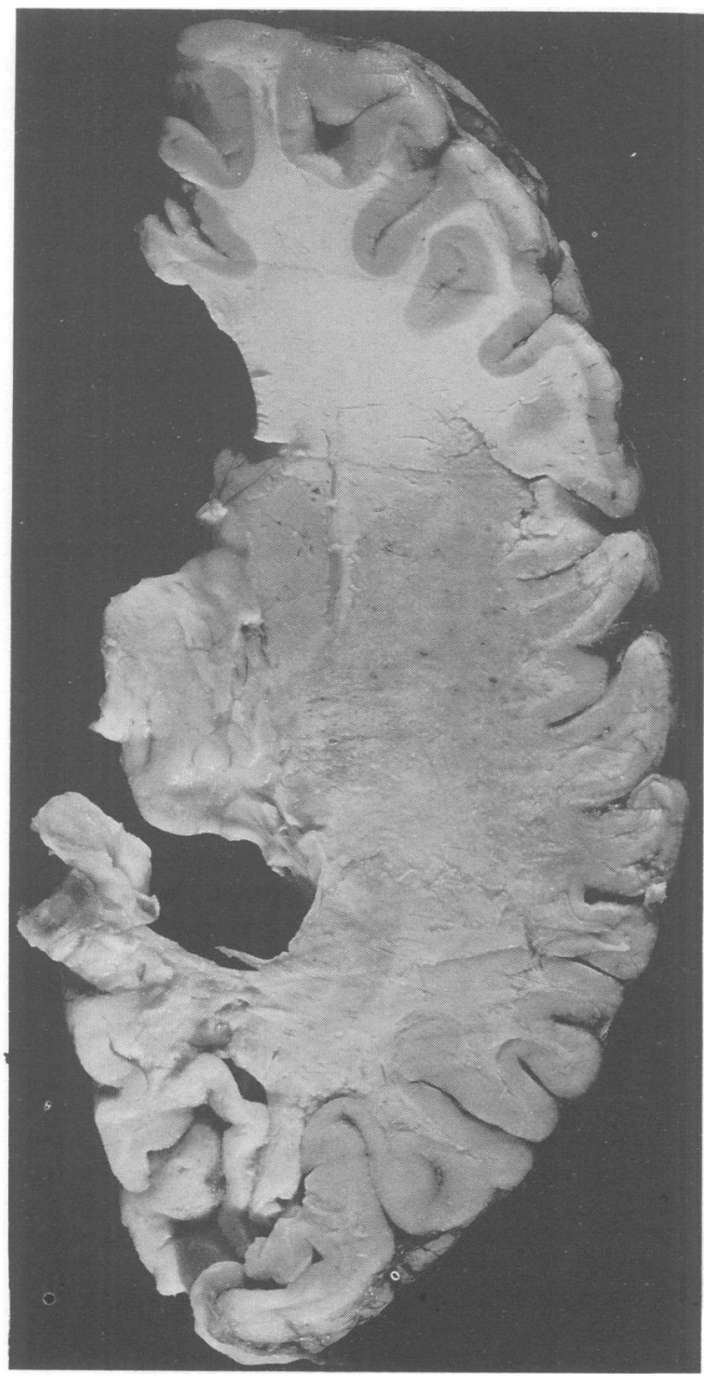

Fig 5 Case 2: horizontal section of the right cerebral hemisphere showing discolouration of the white matter of the occipital and parietal lobes. hexacosanoic to docosanoic acid ratios (C26:0/C22:0) in severely affected areas were 86.4 for Case 1 , and 33.6 for Case 2. These results confirm that both the patients suffered from adrenoleukodystrophy.

These findings are described in greater detail in another study of several cases of ALD and other demyelinating conditions. $^{23}$

\section{Discussion}

The most likely pattern of inheritance accounting for the occurrence of ALD in females is that of a sexlinked disease in which carriers occasionally manifest features to a clinically significant degree of severity. This may occur in either of two ways: firstly, in a carrier, an additional spontaneous mutation or deletion may occur in the paternally derived $\mathrm{X}$ chromosome leading to a homozygous state. Secondly, due to the vagaries of lyonisation, a female heterozygote might exhibit the disease because the $\mathrm{X}$ chromosome carrying the normal allele could be preferentially inactivated. Whilst the chance of the former explanation occurring is slim, clinical manifestation is seen in other sex-linked recessive conditions such as Fabry's disease ${ }^{24}$ and Duchenne muscular dystrophy. ${ }^{2526}$ Moser et al ${ }^{27}$ have demonstrated that female carriers of ALD have an abnormal long chain fatty acid ratio in cultured skin fibroblasts. Therefore, it is probable that in a few instances, such carriers of ALD also may exhibit a degree of expression of the abnormal gene such that it becomes clinically significant. In the present study the son's clinical, pathological and biochemical picture was so typical that there was nothing to suggest that he suffered from anything other than the usual sex-linked form of ALD. Therefore, it must be concluded that the mother was a manifesting heterozygote.

Reports of females with ALD are still very rare, and this study joins three others ${ }^{6} 1120$ where descendants of affected women showed evidence of the same disease. In addition, we had the opportunity to perform a full post mortem neuropathological examination, including electron microscopy, as well as biochemistry.

Although rare, ALD is a diagnosis worth considering in patients of either sex with adult onset multifocal cerebral disease. If, as in our cases the CT scan is typical, this would substantiate the diagnosis, which could be confirmed biochemically by ACTH stimulation, and conclusively, by analysis of long chain fatty acids in cultured skin fibroblasts. Brain biopsy would therefore generally be unnecessary.

The authors thank Professor Trefor Jenkins of the Department of Human Genetics for his advice, Dr James I Phillips for the electron microscopy, $\mathrm{Mr}$ Bongami Zulu and Mrs Ilka von Schirp for their tech- 


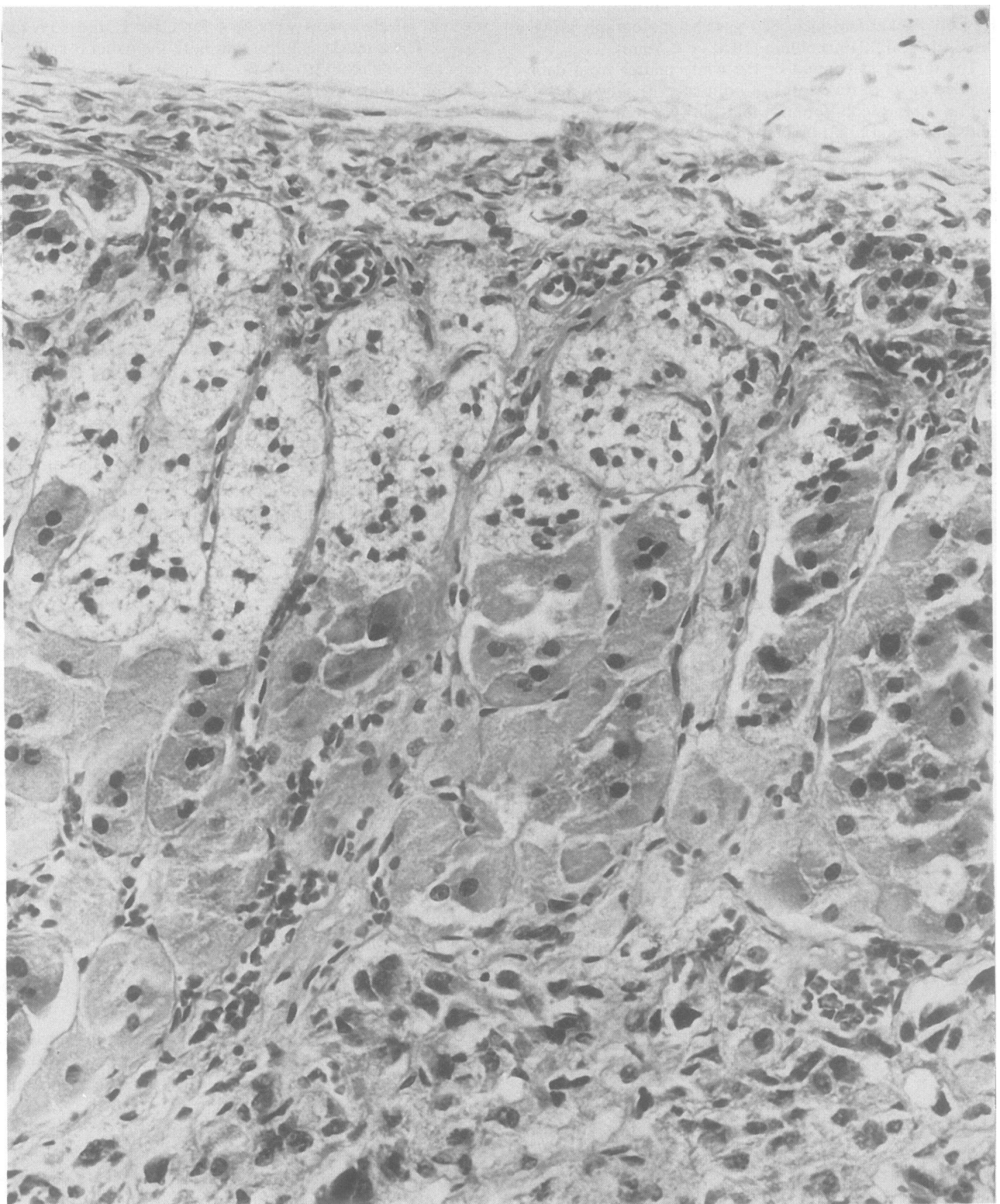

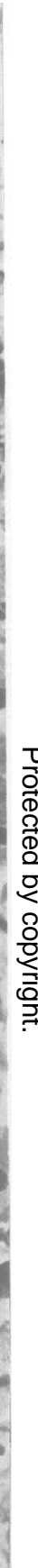

Fig 6 Case 2: micrograph of the atrophic adrenal gland showing thinning the cortex and ballooning of cortical cells. (Haematoxylin and eosin, $\times 323$ ). 


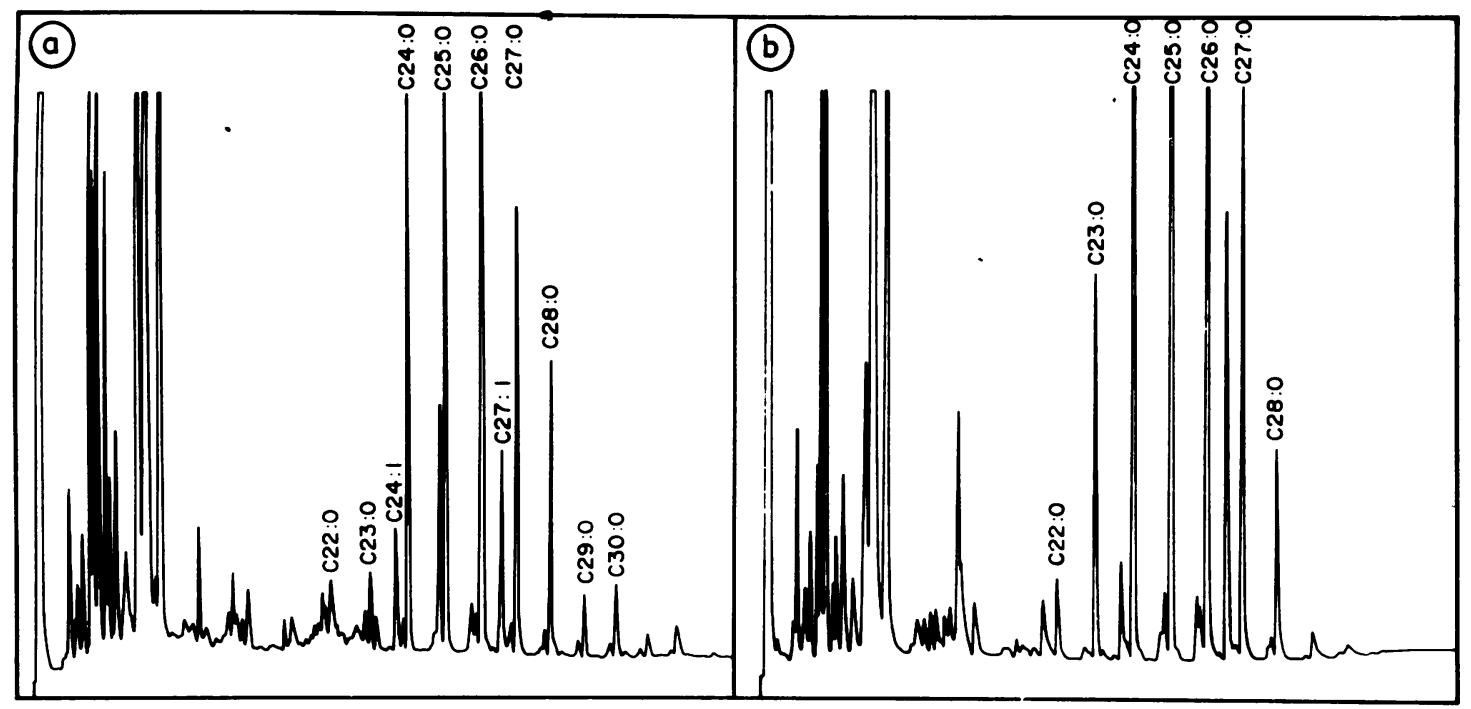

Fig 7 Gas chromatographic recordings of long chain fatty acid methylesters prepared from the cholesterol ester fraction of cerebral white matter from the son (Case 2), and his mother (Case 1) in panels $A$ and B respectively. The homologous series of saturated long chain fatty acids is indicated according to the number of carbon atoms $(C 22: 0, C 23: 0$ etc). The monounsaturated derivations are indicated by C24:1 and C27:1.

nical expertise, Mrs Rose Kunde and Miss Verena White for the secretarial work, Mr Detlef Knoll for the biochemical analysis and Mr Melvyn Anderson for the photography.

\section{References}

1 Schaumburg HH, Powers JM, Raine CS, Suzuki K, Richardson EP. Adrenoleukodystrophy: a clinical and pathological study of 17 cases. Arch Neurol 1975;32:577-91.

2 Powers JM, Schaumburg HH. The adrenal cortex in adrenoleukodystrophy. Arch Pathol 1973;96:305-10.

3 Powell H, Tindall R, Schultz P, Paa D, O'Brien J, Lampert P. Adrenoleukodystrophy: electron microscopic finding. Arch Neurol 1975;32:250-60.

4 Ghatak NR, Nochlin D, Peris M, Myer EC. Morphology and distribution of cytoplasmic inclusions in adrenoleukodystrophy. J Neurol Sci 1981;50:391-8.

5 Igarshi M, Schaumburg HH, Powers JM, Kishimoto Y, Kolodny E, Suzuki K. Fatty acid abnormality in adrenoleukodystrophy. J Neurochem 1976;26:851-60.

6 Moser HW, Moser AB, Kawamura N, et al. Adrenoleukodystrophy: studies of the phenotype, genetics and biochemistry. Johns Hopkins Med J 1980;147:217-25.

7 Singh I, Moser AE, Goldfischer S, Moser HW. Lignoceric acid is oxidised in the peroxisome: implications for the Zellweger cerebro-hepato-renal syndrome and adrenoleukodystrophy. Proc Natl Acad Sci USA 1984;81:4203-7.

8 Griffin JW, Goren E, Schaumburg HH, Engel WK, Loriaux L. Adrenomyeloneuropathy a probable variant of adrenoleukodystrophy. I Clinical and endocrinologic aspects. Neurology 1977;27:1107-13.

9 Schaumburg HH, Powers JM, Raine CS, et al. Adrenomyeloneuropathy: a probable variant of adrenoleukodystrophy. II
General pathologic, neuropathologic and biochemical aspects. Neurology 1977;27:1114-9.

10 Davis LE, Snyder RD, Orth DN, Nicholson WE, Kornfeld M, Seelinger DF. Adrenoleukodystrophy and adrenomyeloneuropathy associated with partial adrenal insufficiency in three generations of a kindred. Am J Med 1979;66:342-7.

11 O'Neill BP, Marmion LC, Feringa ER. The adrenoleukomyeloneuropathy complex: expression in four generations. Neurology 1981;31:151-6.

12 Ulrich J, Herschkowitz N, Heitz P, Sigrist T, Baerlocher P. Adrenoleukodystrophy: preliminary report of a connatal case. Light and electron microscopical, immunohistochemical and biochemical findings. Acta Neuropathol (Berl) 1978;43:77-83.

13 Poulos A, Sharp P, Fellenberg AJ, Danks DM. Cerebro-hepatorenal (Zellweger) syndrome, adrenoleukodystrophy, and Refsum's disease: plasma changes and skin fibroblast phytanic acid oxidase. Hum Genet 1985;70:172-7.

14 Kelley RI, Datta NS, Dobyns WB, et al. Neonatal adrenoleukodystrophy: new cases, biochemical studies, and differentiation from Zellweger and related peroxisomal polydystrophy syndromes. Am J Med Genet 1986;23:869-901.

15 Aubourg P, Scotts J, Rocchiccioli F, Feldmann-Aputrat D, Robain O. Neonatal adrenoleukodystrophy. J Neurol Neurosurg Psychiatry 1986;49:77-86.

16 Migeon BR, Moser HW, Moser AB, Axelman J, Sillence D, Norum RA. Adrenoleukodystrophy: evidence for X-linkage, inactivation and selection favoring the mutant allele in heterozygous cells. Proc Natl Acad Sci USA 1981;78:5066-70.

17 Penman RWB. Addison's disease in association with spastic paraplegia. Br Med J 1960;1:402.

18 Pilz P, Schiener P. Kombination von Morbus Addison und Morbus Schilder bei einer 43 jährigen frau. Acta Neuropathol (Berl) 1973;26:357-60.

19 Heffungs W, Hameister H, Ropers HH. Addison's disease and cerebral sclerosis in an apparently heterozygous girl: evidence for inactivation of the adrenoleukodystrophy locus. Clin Genet 1980;18:184-8. 
20 Morariu MA, Chason JL, Norum RA, Moser HW, Migeon B. Adrenoleukodystrophy variant in a heterozygous female. Neurology 1982;32:A81.

21 Molzer B, Bernheimer H, Budka H, Pilz P, Toifl K. Accumulation of very long chain fatty acids is common to 3 variants of adrenoleukodystrophy: classical ALD, atypical ALD (female patient) and adrenomyeloneuropathy. J Neurol Sci 1981;51: 301-10.

22 Pretorius PJ, Reinecke CJ, Op't Hof J. Biochemical evidence for clinically diagnosed adrenoleukodystrophy in two brothers. $S$ Afr Med J 1984;65:860-2.

23 Reinecke CJ, Knoll DP, Pretorius PJ, Steyn HS, Simpson RHW. The correlation between biochemical and histopathological findings in adrenoleukodystrophy. $J$ Neurol Sci 1985;70: 21-38.

24 Wise D, Wallace HJ, Jellinek EH. Angiokeratoma corporis diffusum: a clinical study of eight affected families. $Q \mathrm{~J}$ Med 1962;31:177-206.

25 Moser H, Emery AEH. The manifesting carrier in Duchenne muscular dystrophy. Clin Genet 1974;5:271-84.

26 Yoshioka M. Clinically manifesting carriers in Duchenne muscular dystrophy. Clin Genet 1981;20:6-12.

27 Moser HW, Moser AE, Trojak JE, Supplee SW. Identification of female carriers of adrenoleukodystrophy. J Pediatr 1983;103: 54-59. 